\title{
An effect evaluation of the psychosocial work environment of a university unit after a successfully implemented employeeship program
}

\begin{tabular}{|r|l|}
\hline Journal: & International Journal of Workplace Health Management \\
\hline Manuscript ID & IJWHM-08-2017-0065.R1 \\
\hline Manuscript Type: & Research Paper \\
\hline Keywords: & $\begin{array}{l}\text { organizational intervention, effect evaluation, process evaluation, } \\
\text { psychosocial work environment }\end{array}$ \\
\hline \multicolumn{2}{|l}{} \\
\hline
\end{tabular}




\title{
An effect evaluation of the psychosocial work environment of a university unit after a successfully implemented employeeship program
}

\begin{abstract}
Purpose: This study examined whether a successful implementation of an intervention could result in an effect evaluated independently from a process evaluation. It achieved this by evaluating the effects of an intervention, the 'employeeship program', designed to strengthen the psychosocial work environment through raising employees' awareness and competence in interpersonal relationships and increasing their responsibility for their everyday work and working environment.

Design/methodology/approach: An employeeship intervention program was developed to improve the psychosocial work environment through reducing conflict among employees and strengthening the social community, empowering leadership, and increasing trust in management. An earlier process evaluation of the program found that it had been implemented successfully. The present effect evaluation supplemented this by examining its effect on the psychosocial work environment using two waves of the organization's internal survey and comparing changes in the intervention unit at two points and against the rest of the organization.
\end{abstract}

Findings: The intervention was effective in improving the psychosocial work environment through reducing conflicts among employees and strengthening the social community, empowering leadership, and increasing trust in management

Research limitations/implications: More attention should be paid to developing and increasing positive while simultaneously reducing negative psychosocial experiences, as this employeeship intervention demonstrated. 
Practical implications: An intervention focusing on employeeship is an effective way to achieve a healthier psychosocial work environment with demonstrable benefits for individuals and the working unit.

Originality/value: Although organizational-level interventions are complex processes, evaluations that focus on process and effect can offer insights into the workings of successful interventions.

Keywords: process evaluation, effect evaluation, organizational intervention, psychosocial work environment 
Interventions to improve organizations are undertaken quite often in both practice and research, but relatively little research focuses on both the implementation process and the effects of an intervention. In 2013 an organizational intervention focusing on developing employeeship in a university unit was carried out and its implementation process of an organizational intervention evaluated (Authors, 2015). The intervention was based on the premise that positive psychosocial experiences should be increased while simultaneously reducing negative experiences. Specifically, it was designed to strengthen the psychosocial work environment through raising employees' awareness and competence in interpersonal relationships and increasing their responsibility for their everyday work and working environment. The process evaluation found the intervention to be successful (Authors, 2015). The present study describes the follow-up effect evaluation of the intervention focusing on changes in the psychosocial work environment across the whole university conducted before and after the intervention was implemented. As such, it supplements the evaluation of the intervention and aims to show how evaluations that focus on process and effect can offer insights into the workings of successful interventions. Next, we discuss what we know about intervention evaluation before we briefly outline the intervention and describe its evaluation.

Successful interventions consist of both a good content that aims to change a target outcome and a good process that aims for a smooth implementation of the intervention. A process evaluation is defined as the evaluation of "individual, collective or management perceptions and actions in implementing any intervention and their influence on the overall result of the intervention” (Nytrö, Saksvik, Mikkelsen, Bohle, \& Quinlan, 2000; 214). An outcome or effect evaluation is defined as the result of an intervention in changing organizational output like stress, well-being, absenteeism or financial results. Although an intervention can be very well implemented it may not result in any (measurable) outcomes. A comprehensive and informative evaluation should include both process and outcome 
evaluation, but often researchers conduct only one type, due to time or resource restrictions, making the evaluation and lessons learned from it only partial.

Evaluation methodology in organizational health interventions is still in its infancy, but a special issue in Stress \& Health in 2016 had aims to present advancements in evaluation methods to provide answers to "what works" questions in this field (Karanika-Murray, Biron, \& Saksvik, 2016). This study examined whether a successful implementation of an intervention could result in an effect evaluated independently from the process evaluation. Organizations may invest a lot of time and resources to implement an intervention. They secure broad participation from all employees, they involve all leaders, they include activities that create motivation and creativity among the participants, and they make use of resources (like external consultants) to ensure that everything goes smoothly. Calls have been made for an increased focus on evaluating the way in which interventions are implemented and how this affects their outcomes (Biron \& Karanika-Murray, 2014; Egan, Bambra, Petticrew, \& Whitehead, 2009). Biron and Karanika-Murray (2014) reviewed studies of organizational health intervention programs and found that the two most commonly studied issues were the effects of an intervention program and the factors influencing a specific outcome. Thus, they posited that organizational health intervention programs tend to focus on evaluating results or outcomes rather than processes. If you invest a lot in implementing an intervention you may take it for granted that absenteeism decline, cooperation among employees is strengthened, conflict level is reduced, or even productivity will benefit. Too often no direct measures of targeted effects are offered or no documentation of the connected implementation process exists.

In this regard, two studies have investigated employees' perceptions of intervention implementation in relation to their health outcomes (Nielsen, Randall, \& Albertsen, 2007; Randall, Nielsen, \& Tvedt, 2009). In a study by Randall and colleagues (2009), employees' 
perceptions of their line managers' attitudes and actions were more important for their future health status than their exposure to the content of the organizational intervention, which was team training. Employees' perceptions of information and communication concerning an intervention have also been related to the intervention effects and employees' more positive perceptions of information and communication concerning an intervention have also been related to stronger intervention effects (Jimmieson, Terry, \& Callan, 2004). Employees with higher levels of participation in the change process also show less resistance to change and more achievement of goals and commitment to their organization (Lines, 2004). Similarly, high levels of participation in the change process were associated with low levels of behavioral stress symptoms and higher job satisfaction in post-intervention measurements (Nielsen et al., 2007), reduced work demands, increased social support, and lower stress levels (Eklöf, Ingelgård, \& Hagberg, 2004). These results provide further support for the suggestion that factors concerning the process of program implementation have a major impact on program effects (Randall et al., 2009), often over and above the content of the intervention. Therefore, both process and outcome (effect) evaluation is necessary, as used in this project.

The main data source for this study was the database from ARK (Arbeidsmiljø og klimaundersøkelser, Work Environment and Social Climate Surveys) (Undebakke, Innstrand, Anthun, \& Christensen, 2015). The ARK project is especially adapted for knowledge intensive workplaces, using the KIWEST questionnaire (Knowledge Intensive Working Environment Survey Target). ARK is an intervention framework where the aim is to improve the psychosocial work environment and employee well-being. Building on the Job Demands Resources Model, ARK focuses on developing employees' resources through participatory processes, and is implemented through a series of specific interventions targeting different outcomes. At the Norwegian University of Science and Technology (NTNU) approximately 
6,300 employees have been invited to participate in the survey. This evaluation was

conducted by the central organizational staff of the university and had no direct link to this project. This made it possible to evaluate the change over time on several issues such as social community, empowering leadership, interpersonal conflict, and trust in management. The intervention presented here was not linked to the overall ARK program.

\section{The Intervention}

This evaluation focused on the effect of an intervention named the employeeship program, which was aimed primarily at strengthening the psychosocial work environment, specifically by raising the employees' awareness of and competence in interpersonal relationships, thereby increasing employees' ability to take responsibility for their everyday work and their working environment. The process evaluation of the employeeship program are outlined in detail in Authors (2015) and is briefly outlined here, because of limited space (for further information, the readers should contact the authors). In short, this participatory intervention aimed to increase employee's awareness and skills regarding interpersonal relationships. The intervention consisted of three mandatory workshops, spread over a period of six to nine months. While a crucial aim of the workshops was to reduce interpersonal conflict, they were also aimed at promoting positive aspects at the workplace, such as more positive interactions among the employees. The main objective in the first workshop was a positive focus on employee diversity, by using the Diversity Icebreaker Test (Human Factors, 2013). This test measures preferences for communication, interaction, and different problem-solving styles. Individual employees' strengths and weaknesses and organizational strategies to overcome these weaknesses were identified and discussed. A second focus in the workshops was practical training in teamwork, communication, and customer service. Hence, the second workshop consisted of practical exercises in collaboration and communication, and the third workshop included a brief course in customer communication skills. 
The process evaluation from this intervention suggested that the participants perceived the Diversity Icebreaker Test as a useful tool for facilitating reflection, discussion, and communication among employees. Aspects like getting to know each other better and developing a shared vocabulary were explicitly attributed as positive outcomes from the tool. The process evaluation further identified two key factors in successfully implementing the intervention: leadership and communication. The statistical analysis suggested that leadership explained most of the variation in employees' perceptions of the intervention as successful, whereas the qualitative analysis provided information about the importance of providing sufficient and understandable information about the intervention's purpose and implementation. The evaluation also highlighted the usefulness of practical training activities. However, if not supplemented by effect evaluation, process evaluation is only partial. Therefore, this study supplemented findings on the implementation of the employeeship program by examining outcome issues relevant to its effectiveness.

Human strengths such as courage, insight, perseverance, and hope act as buffers against negative experiences such as mental illness and interpersonal conflict. More attention should be paid on developing and increasing positive psychosocial experiences, while simultaneously indirectly reducing the negative. This has now become an improvement over the traditional approach: reducing stress and improving mental and physical health of employees by introducing positive change initiatives (Biron, Burke, \& Cooper, 2014; Christensen, Saksvik, \& Karanika-Murray, 2017).

\section{Approach to Effect Evaluation}

Based on the KIWEST survey it was assumed that it should be possible to evaluate the change over time on selected issues for the intervention unit (IU) compared to the rest of the NTNU. If an effect could be found in a target variable for the IU group, and this effect was not found for the rest of the NTNU (control group), it would be reasonable to assume this effect may 
stem from the intervention efforts. Here, social community from the KIWEST survey was chosen as an indicator of improved interactions. A third aim of the intervention was to strengthen the leadership of the unit. Here, empowering leadership and trust in management were selected as indicators from the KIWEST survey. Based on the aim of the interventions the following evaluation hypotheses were examined:

Hypothesis 1: Those receiving the intervention will report a reduction of interpersonal conflict compared to those not receiving the intervention.

Hypothesis 2: Those receiving the intervention will report an improvement of interpersonal relationships compared to those not receiving the intervention.

Hypothesis 3: Reduced interpersonal conflict and improvement of interpersonal relationships as experienced by those receiving the intervention is linked to empowering leadership and increased trust.

\section{Method \\ Study design}

In 2012, the intervention unit (IU) at NTNU initiated an intervention called the 'employeeship program'. The intervention was implemented because a survey showed that the unit had psychosocial work environments in need of improvement and that interpersonal conflicts were widespread. The interpretation of the results from this survey and the selection of the intervention unit (for the employeeship program) were carried out by an external consultancy firm. A description of the intervention can be found above and, in more detail, in Authors (2015). The ARK-survey undertaken in 2012 was administered at the whole university and represents the baseline for the effect evaluation.

The intervention was launched in February 2012 (after the first survey) and completed in March 2013. In October 2014, the ARK-survey was administered again across the whole university $(\mathrm{N}=3,842)$, including the IU $(\mathrm{n}=59)$. See Table 1. 
[Insert Table 1 about here]

\section{The survey (ARK)}

ARK is a working environment and working climate intervention tool developed by four of Norway's largest universities for use in the academic sector. It is grounded in theory and has been shown to be a valid and reliable tool for workplace surveys, interventions, and research (Undebakke, et al., 2015). It investigates the psychosocial conditions in knowledge-intensive organizations in a systematic way and includes important psychosocial working environment factors with the aim to develop organizations' working environment and climate. ARK consists of several parts: 1) the Knowledge Intensive Work Environment Survey Target (KIWEST), 2) Factsheets I and II giving key information about the units about size, organization etc., 3) a structured guideline for follow-up and feedback meetings regarding results of KIWEST, and 4) a database called the ARK Research Platform that stores data from all surveys and is available for research. In taking a closer look at some of the parts of ARK, KIWEST examines employees' individual experiences of their perceived work environment and is thus answered by all employees.

KIWEST examines employees' individual experiences of psychosocial working environment factors that are seen as important for the university sector. KIWEST I was used in 2012 and KIWEST II was used in 2014, and there are some minor differences (described below) in what scales these questionnaires used to measure certain factors. The survey included questions covering employee demographic information, subjective occupational health and other work-environment and climate scales including the ones used in the investigation. The questionnaire used in this study was based on well-established and previously validated instruments used to assess occupational health and well-being. The following were selected to address the research question: 
Interpersonal conflict. Interpersonal conflict was measured with three items from (Näswall et al., 2010); "Intrigues in my workplace impair the work climate.", "There is a great deal of tension in the workplace due to prestige and conflicts", and "My work is hampered by the existence of power struggle and territorial thinking at my workplace "Responses were measured on a 5-point scale ranging from 1 ("Strongly disagree") to 5 ("Strongly agree"). A high score indicates that the respondents to a high degree are negatively affected by conflicts between colleagues. Cronbach's alpha for Interpersonal Conflict was .90 pre-intervention and .86 post-intervention.

Social community at work. Social community at work was measured by a scale from the Copenhagen Psychosocial Questionnaire (COPSOQ II) (Pejtersen, Kristensen, Borg, \& Bjorner, 2010) consisting of three items; "Is there a good atmosphere between you and your colleagues?", "Is there good cooperation between the colleagues at work?" and "Do you feel part of a community at your place of work?" Responses were measured on a 5point scale ranging from 1 ("To a very small extent", to 5 ("To a very large extent". A high score indicates that respondents experience a high degree of social community with colleagues in their own unit. Cronbach's alpha for Social Community was .85 preintervention and .83 post-intervention.

Empowering leadership. Empowering leadership was measured by a scale from the General Nordic Questionnaire for Psychological and Social Factors at Work (QPS-Nordic) (Dallner et al., 2000) consisting of three items; "Does your immediate superior encourage you to participate in important decisions?", Does your immediate superior encourage you to speak up, when you have different opinions? And "Does your immediate superior help you develop your skills?”.” Responses were measured on a 5-point scale ranging from 1 (“Very seldom/never"to 5 (“Very often/always";). Cronbach's alpha for this scale was .87 preintervention and .90 post-intervention. 
Trust in management. Trust in management was measured by a scale from COPSOQ II (Pejtersen et al., 2010); consisting of four items; "Can you trust the information that comes from the management?", Does the management trust the employees to do their work well?, Does the management withhold important information from the employees? (R), and "Are the employees able to express their views and feelings?". Responses were measured on a 5-point scale ranging from 1 ("To a very small extent", to 5 ("To a very large extent"). A high score indicates a high degree of perceived trust in management. Cronbach's alpha for Trust in Management was .83 pre-intervention and .84 post-intervention.

The questionnaire was sent to all university employees by e-mail, using the Select Survey (www.selectsurvey.net) online survey system. Reminders were sent by email about three and six weeks later. If employees answered fewer than half of the questions within an index, their survey responses were excluded from the analyses.

\section{Analytical approach}

A two-way independent ANOVA was used to compare the intervention unit (IU) with the rest of NTNU. In addition, a two-way independent ANCOVA was also conducted to examine the effects of Empowering Leadership and Trust in Management on the dependent variables. All analyses were conducted using IBM SPSS (IBM, 2015).

\section{Results}

\section{Descriptive statistics}

[Insert Table 2 about here]

As Table 2 shows, all scales had internal reliability over 0.7 , which is considered the lowest acceptable (Tavakol \& Dennick, 2011).

For Interpersonal Conflict the ANOVA analysis showed an interaction effect; Interpersonal Conflict had decreased over time for the IU, but had increased for the rest of the 
university $(\mathrm{F}(1,6901)=5.38, p<.05$; See Figure 1$)$. Hypothesis 1 was therefore supported.

[Insert Figure 1 about here]

For Social Community the ANOVA analysis showed a significant main effect of time $(\mathrm{F}(1,6936)=21,93, p<.01)$ and a significant interaction effect where Social Community had increased more over time for the IU than it had within the rest of the university $(\mathrm{F}(1,6936)=$ $5,13, p<.05$; See Figure 2). To pass Levene's test the three indexes Social Community, Trust in Management and Empowering Leadership had to undergo cube-transformation, which explains the values on the y-axis in Figures 3 and 4 ranging from 1 to 125.

[Insert Figure 2 about here]

After including Empowering Leadership and Trust in Management as covariates in an ANCOVA analysis with Interpersonal Conflict as dependent variable, the results showed a significant main effect for group belonging $(\mathrm{F}(1,6625)=7,25, p<.01)$, as well as a significant interaction effect $(\mathrm{F}(1,6625)=10,19, p<.01)$. Both covariates were significantly related to Interpersonal Conflict, Empowering Leadership $(\mathrm{F}(1,6625)=81,64, p<.001)$ and Trust in Management $(\mathrm{F}(1,6625)=1611,35, p<.001)$. See Figure 3.

[Insert Figure 3 about here]

Covariates appearing in the model are evaluated at the following values: Empowering Leadership [3.58], Trust in Management [3.89]. Social Community and Empowering Leadership had improved for the IU, and also for the rest of the university. Social Community had changed for the IU from $M=3.62$ in 2012 to $M=4.16$ in 2014. This difference, was found to be significant ( $p=.001$ ). The same was found for NTNU, from $M=3.80$ in 2012 to 3.98 in 2014. This change was also significant $(p<.001)$.

For Empowering Leadership an improvement in the IU was found between $2012(\mathrm{M}=$ $2.87)$ and $2014(\mathrm{M}=3.35)$. This improvement was found to be significant $(p=0.023)$. For NTNU it also was an improvement $(M=3.26$ to $M=3.85)$ and this change was significant. 
For Trust in Management on average, the IU had slightly higher scores in 2014 ( $M=$ 3.63) than in $2012(M=3.635)$, and this was also shown in the NTNU scores in $2012(M=$ 3.88 and $2014(M=3.91)$, where only the latter was significant $(p<.05)$.

When including Empowering Leadership and Trust in Management as covariates in an ANCOVA analysis with Social Community as dependent variable, the results show a significant main effect for group belonging $(\mathrm{F}(1,6643)=9,37, p<.001)$, a significant main effect of time $(\mathrm{F}(1,6643)=15,80, p<.001)$, as well as a significant interaction effect $(\mathrm{F}(1$, $6643)=7,54, p<.01)$. Both covariates were significantly related to Interpersonal Conflict, Empowering Leadership $(\mathrm{F}(1,6643)=336,27, p<.001)$ and Trust in Management $(\mathrm{F}(1,6643)$ $=1110,85, p<.001$; see Figure 4). Hypothesis 3 was therefore supported.

[Insert Figure 4 about here]

Covariates appearing in the model are evaluated at the following values: Empowering Leadership [56.92], Trust in Management [65.12].

\section{Discussion}

Overall, the intervention had a positive effect on some of the variables in the psychosocial work environment in the intervention unit. All study hypotheses were supported: both interpersonal conflict and social community had improved for the intervention unit compared to NTNU. It can therefore be concluded that the intervention was successful in improving the psychosocial work environment through reducing conflicts among employees and strengthening the social community, empowering leadership, and increasing trust in management.

Although the evaluation showed that the employeeship intervention had been implemented well, information that emerged in retrospect indicated that more activities had been conducted in the intervention unit both before and after the intervention. These undocumented activities may have had an impact on the outcomes of the intervention or its 
long-term effects. Therefore, longitudinal follow-up and action research may be necessary to more comprehensively understand the mechanisms behind these intervention changes. This is in line with the results of a parallel project (Lien \& Saksvik, 2016). Conducting and documenting action research initiatives is important in order to understand how and why an intervention succeeds or derails. Action research can also be a useful tool for correcting the implementation progression (Greenwood \& Levin, 2006). It also yields much richer data and understanding about the true workings of an intervention process, as it relates to both time and content. The action research activities that have been conducted in the project are currently being investigated, including the activities undertaken by an internal work group.

The key starting point of this study is that a successful intervention process promotes positive intervention effects. Specifically, the study focused on two intervention outcomes (interpersonal conflict and social community) and further provided evidence that two aspects of the intervention process (empowering leadership and trust in management), are important aspects supporting the intervention process that ought to be considered in intervention implementation. By evaluating the implementation of the intervention using a longitudinal and independent survey, it is possible to provide more strength to this argument. First, using a longitudinal approach allows to compare the participant's ratings of their psychosocial work environment prior to and after the intervention program. Second, because the survey was implemented across the whole university it is possible to compare the results from the intervention unit with the total scores for the university. Third, although using self-reports or other survey methods is quite frequent in evaluating interventions (Abildgaard, Saksvik, \& Nielsen, 2016), this approach uses an independent survey that was not directly associated with the intervention. And finally, collecting data from both the implementation process and the intervention effect offers a richer understanding of what caused the observed effects (Biron \& Karanika-Murray, 2014). Next, the findings from the evaluation study are discussed, insights 
regarding the content of the intervention and contextual factors like mandatory participation and concurrent activities are outlined, and how this may relate to the observed effect of improved psychosocial work environment is examined.

The content of an intervention is, in many cases, less important than how the intervention is implemented. Biggs and Brough (2015) suggest that non-significant or negative results more often are caused by contextual and process factors than by the content of given programs or activities. In addition, Semmer (2011) claims that differentiating between participation and content in what contributes to positive intervention effects proposes a challenge (e.g., the Hawthorne effect). Thus, there are several factors in the organizational context which can explain some aspect of the positive intervention outcome.

In addition, broader contextual factors ought to be considered in order to understand the effectiveness of an intervention. Participation in the workshops was mandatory for all employees in the unit. This is in line with researchers emphasizing the importance of participation in the intervention process (Biron \& Karanika-Murray, 2014; Giæver, Vaag, \& Wennes, 2017). Giæver and colleagues, for example, recommend that interventions should aim to include all individuals in the organization to achieve a best possible collective effect. In their line of research, the researchers found unexpected negative effects in terms of differences between participants and non-participants. In particular, participants showed more organizational commitment and engagement, and an improvement in the psychosocial work environment, compared to non-participants (Giæver et al., 2017; Milch, Vaag, Giæver, \& Saksvik, 2013). Kawakami and Kobayashi (2015) found similar effects. They investigated how employees used a mental health action checklist designed to improve the psychosocial work environment, and found that organizations with more than $50 \%$ employees participating in the intervention program reported decreased psychological strain and increased job performance. This was not the case for organizations with lower participating rates. Nielsen 
(2013) further proposes that merely participating in interventions could lead to gaining new perspectives on work life, as well as learning how to collectively question established work procedures through mechanisms like job crafting. Taken together, these findings suggest that the positive effect observed in the current intervention unit can partly be explained by the fact that the intervention targeted all employees.

Another contextual factor worth mentioning is temporality. A longitudinal approach presupposes a certain time interval between pre- and post-intervention surveys, on one hand, and between the intervention and the post-intervention survey, on the other. However, there are no clear empirical recommendations of an optimal time frame between different measurements (Navarro, Roe, \& Artiles, 2015). Some researchers suggest at least three months between leadership training and post-measurement (Donohoe \& Kelloway, 2014), while other researchers recommend differentiating between short-term and long-term effects in evaluating intervention effects (Jauvin \& Vézina, 2015; Milch et al., 2013). Regarding the current study however, the temporal issue of most concern is the concurrent activities implemented in the intervention unit, and how these activities may or may not have affected the interaction between the intervention process and the observed outcome. Some of these concurrent activities included training in conflict management and external managerial support and guidance. How can researchers be certain that the observed effect in the intervention unit is caused by the employeeship program and not concurrent activities? Perhaps maintaining a focus on developing and improving the psychosocial work environment across different activities is the key to success? There are no clear answers to these questions, partly because evaluating all activities designed to improve some aspects of the working life goes beyond the study. In addition, several of the other university units were also undergoing various activities. If simply participating in an activity was linked to a positive outcome, the intervention unit examined here would not show different outcomes 
from the rest of the university. However, merely initiating activities meant to improve aspects of the psychosocial work environment is rarely sufficient, because how ready the employees are, how the intervention activities are perceived by employees and management, and to which degree these activities are incorporated in the unit's daily life also play an important role (Biron \& Karanika-Murray, 2014). Thus, evaluating the implementation process and different contextual factors during all the intervention's phases, and how these factors relate to observed outcomes, are keys to understanding what works in organizational interventions (Martin, Karanika-Murray, Biron, \& Sanderson, 2016). As such, the findings indicate that there is a link between a successful implementation process and positive intervention results and, in fact, that the implementation process matters.

The most relevant variables related to the content of the intervention were selected, which also concurred with insights and learnings from the implementation of the intervention, but whether there was a general effect in the psychosocial work environment was not examined. Insights from this parallel work (this study and Authors, 2015) indicates that it is difficult to achieve a general effect. Intervention researchers may be too optimistic about generating large or widespread changes across the whole organization. Targeted changes that touch the core of an identified problem or challenge may be more beneficial for the organization than broader changes to the whole organization (Karanika-Murray \& Weyman, 2013).

\section{Methodological considerations}

It is important to outline some of the strengths and limitations of this effect evaluation, including issues regarding experimental design (e.g. baseline measurements and randomization of participants) and limitations with self-reports measures (e.g. social desirability and self-serving bias). 
Even though there was no true baseline in this study, one important strength was the fact that data were collected on two occasions. The fact that participants were assessed twice made it possible to make cause and effect inferences. The fact that the research design in this study included both an intervention group and a control group represents another strength. It is important to note that because the first survey (KIWEST I) was conducted a while after the intervention had begun (but before it had been completed), it cannot truly be considered a baseline for the results of the second survey (KIWEST II). It is possible (and perhaps even probable) that the intervention, at the first point of data collection, had already impacted the variables measured. It is also possible that the participants in 2012 had filled in the selfreporting questionnaires more positively than they would have had they not been studied (similar to a Hawthorne effect), or that the participants in the intervention were already experiencing favorable effects. Regardless, it is safe to say that the timing of the data collection may have impacted on the findings.

The results would carry more weight if the participants from 2012 and 2014 could be matched. Unfortunately, it was not possible to match participants from the data sets because it was not possible for such identifiers to be collected, which represents a limitation of the data. Another limitation is that turnover rates not were collected, but it is well known that the turnover is low within the intervention unit and in NTNU as a whole and NTNU official statistics show that the average turnover rate in the intervention unit within the actual period was $6.5 \%$. Matched participation would also have made it possible to conduct a repeated measures ANOVA, increasing the strength of the study.

Another limitation to this effect evaluation is that the survey did not include open questions and the effect evaluation could have benefitted from the addition of qualitative methodology. Interviews of employees would have added an extra dimension to the analyses, and further relevant information regarding effects could have been uncovered. Interviews 
could also have shed light on potentially important contextual factors. Using a survey or questionnaire may in itself pose problems; there is a chance that the employees were concerned about leadership having access to their individual survey answers, and that this influenced their responses. There is also the possibility that social desirability influenced answers (Donaldson \& Grant-Vallone, 2002). According to Meltzoff (1998) self-report surveys are oftentimes less reliable because of factors such as participants' self-serving biases.

In the current research design, participants were not randomly placed into one experimental group and one control group. Randomization of participants into groups prior to an intervention is regarded as a way to increase the possibility that any changes occurring between the experimental and control group following an intervention can be accredited to the intervention itself. It has been argued that randomization is more challenging but also perhaps not necessary in intervention research (Biron, 2012). This evaluation used more of a quasiexperimental design by using established groups. These groups were thought to be similar as they both came from the same university sample, but they were likely not as similar as they would have been if random assignment was applied.

The scales included in this study are based on standardized and validated measures (Innstrand, Christensen, Undebakke, \& Svarva, 2015). They are also appropriate for the participants in university settings. This represents a strength of this study. The KIWEST is also a rather comprehensive questionnaire that contains a lot of statements, and there is a chance that some bored respondents gave little thought to their answers. Finally, in 2012, participants who did not work with computers were given the option to take the survey on paper rather than electronically. The fact that paper surveys were not handed out in 2014 could mean that certain workers in NTNU were not given the chance to participate.

\section{Conclusion}


It is not easy to conduct a successful intervention and it is equally difficult to document success or failure. In this project the intervention was followed from its launch until three years later when both survey data and other data sources could be used to examine and document a reasonable success. The identified challenges of the unit studied, specifically conflict and social community, had improved compared to the rest of the organization. It is necessary to invest a lot of effort from an organization over time to reach the goal of an intervention.

\section{References}

Abildgaard, J. S., Saksvik, P. Ø., \& Nielsen, K. (2016). How to measure the intervention process? An assessment of qualitative and quantitative approaches to data collection in the process evaluation of organizational interventions. Frontiers in Psychology, 7, 1380. https://doi.org/10.3389/fpsyg.2016.01380

Biggs, A., \& Brough, P. (2015). Explaining intervention success and failure: What works, when, and why? In C. Biron \& M. Karanika-Murray (Eds.), Derailed organizational interventions for stress and well-being (pp. 237-244). Dordrecht: Springer. https://doi.org/10.1007/978-94-017-9867-9_27

Biron, C. (2012). WHAT WORKS, FOR WHOM, IN WHICH CONTEXT? RESEARCHING ORGANIZATIONAL INTERVENTIONS ON STRESS AND WELL-BEING USING REALISTIC EVALUATION PRINCIPLES. In: C. Biron, M., KaranikaMurray \& C. Cooper, C. (Eds). Improving organizational interventions for stress and well-being: Addressing process and context. London: Routledge. ISBN: 978-184872-056-5

Biron, C., Burke, R. J., \& Cooper, C. L. (2014). Creating healthy workplaces: Stress reduction, improved well-being, and organizational effectiveness. Farnham: Gower Publishing Ltd. 
Biron, C., \& Karanika-Murray, M. (2014). Process evaluation for organizational stress and well-being interventions: Implications for theory, method, and practice. International Journal of Stress Management, 21(1), 85-111. https://doi.org/10.1037/a0033227

Christensen, M., Saksvik, P. Ø., \& Karanika-Murray, M. (Eds.). (2017). The positive side of occupational health psychology. Springer. https://doi.org/10.1007/978-3-319-667812

Dallner, M., Elo, A.-L., Gamberale, F., Hottinen, V., Knardahl, S., Lindström, K., ... Ørhede, E. (2000). Validation of the General Nordic Questionnaire (QPSNordic) for psychological and social factors at work (No. 12). Copenhagen: Nordic Council of Ministers.

Donaldson, S. I., \& Grant-Vallone, E. J. (2002). Understanding self-report bias in organizational behavior research. Journal of Business and Psychology, 17(2), 245260. https://doi.org/10.1023/A:1019637632584

Donohoe, M., \& Kelloway, E. K. (2014). Transformational leadership training for managers: Effects on employee well-being. In C. Biron, R. J. Burke, \& C. L. Cooper (Eds.), Creating healthy workplaces: Stress reduction, improved well-being and organizational effectiveness (pp. 205-222). Farnham: Gower Publishing Ltd.

Egan, M., Bambra, C., Petticrew, M., \& Whitehead, M. (2009). Reviewing evidence on complex social interventions: Appraising implementation in systematic reviews of the health effects of organisational-level workplace interventions. Journal of Epidemiology \& Community Health, 63(1), 4-11. https://doi.org/10.1136/jech.2007.071233

Eklöf, M., Ingelgård, A., \& Hagberg, M. (2004). Is participative ergonomics associated with better working environment and health? A study among Swedish white-collar VDU 
users. International Journal of Industrial Ergonomics, 34(5), 355-366.

https://doi.org/10.1016/j.ergon.2004.04.013

Giæver, F., Vaag, J. R., \& Wennes, G. (2017). Choral singing as an arts-based organisational intervention: A qualitative study of employees' experiences. Arts \& Health, 9(1), 2641. https://doi.org/10.1080/17533015.2016.1182564

Greenwood, D., \& Levin, M. (2006). Introduction to action research: Social research for social change. London: SAGE Publications Ltd.

Human Factors. (2013). Diversity Icebreaker. Retrieved November 28, 2013, from http://www.diversityicebreaker.com/home.aspx

IBM. (2015). SPSS Statistics.

Innstrand, S. T., Christensen, M., Undebakke, K. G., \& Svarva, K. (2015). The presentation and preliminary validation of KIWEST using a large sample of Norwegian university staff. Scandinavian Journal of Public Health, 43(8), 855-866. https://doi.org/10.1177/1403494815600562

Jauvin, N., \& Vézina, M. (2015). Ensuring the long-term sustainability of organizational interventions: Potential obstacles to be avoided. In C. Biron \& M. Karanika-Murray (Eds.), Derailed organizational interventions for stress and well-being (pp. 213220). Dordrecht: Springer. https://doi.org/10.1007/978-94-017-9867-9_24

Jimmieson, N. L., Terry, D. J., \& Callan, V. J. (2004). A longitudinal study of employee adaptation to organizational change: The role of change-related information and change-related self-efficacy. Journal of Occupational Health Psychology, 9(1), 1127. https://doi.org/10.1037/1076-8998.9.1.11

Karanika-Murray, M., Biron, C., \& Saksvik, P. Ø. (2016). Editorial. Organizational health interventions: Advances in evaluation methodology. Stress \& Health, 32(4), 255257. https://doi.org/10.1002/smi.2708 
Karanika-Murray, M., \& Weyman, A. (2013). Optimising workplace interventions for health and wellbeing: A commentary on the limitations of the public health perspective within the workplace health arena. International Journal of Workplace Health Management, 6(2), 104-117. doi: 10.1108/IJWHM-11-2011-0024

Kawakami, N., \& Kobayashi, Y. (2015). Increasing worker participation: The mental health action checklist. In C. Biron \& M. Karanika-Murray (Eds.), Derailed organizational interventions for stress and well-being (pp. 175-182). Dordrecht: Springer. https://doi.org/10.1007/978-94-017-9867-9_20

Lien, M., \& Saksvik, P. Ø. (2016). Healthy change processes: A diary study of five organizational units. Establishing a healthy change feedback loop. Stress \& Health, 32(4), 258-269. https://doi.org/10.1002/smi.2698

Lines, R. (2004). Influence of participation in strategic change: Resistance, organizational commitment and change goal achievement. Journal of Change Management, 4(3), 193-215. https://doi.org/10.1080/1469701042000221696

Martin, A., Karanika-Murray, M., Biron, C., \& Sanderson, K. (2016). The psychosocial work environment, employee mental health and organizational interventions: Improving research and practice by taking a multilevel approach. Stress \& Health, 32(3), 201215. https://doi.org/10.1002/smi.2593

Meltzoff, J. (1998). Critical thinking about research: Psychology and related fields. Washington, D.C.: American Psychological Association.

Milch, V., Vaag, J. R., Giæver, F., \& Saksvik, P. Ø. (2013). Building healthy organizations through music and culture interventions. In G. F. Bauer \& G. J. Jenny (Eds.), Salutogenic organizations and change (pp. 291-305). Dordrecht: Springer. https://doi.org/10.1007/978-94-007-6470-5_16 
Näswall, K., Låstad, L., Vetting, T.-S., Larsson, R., Richter, A., \& Sverke, M. (2010). Job insecurity from a gender perspective: Data collection and psychometric properties (No. 1). Stockholm: Department of Psychology, Stockholm University. Retrieved from http://w3.psychology.su.se/psychlib/rapporter/report1.pdf

Navarro, J., Roe, R. A., \& Artiles, M. I. (2015). Taking time seriously: Changing practices and perspectives in work/organizational psychology. Journal of Work and Organizational Psychology, 31(3), 135-145. https://doi.org/10.1016/j.rpto.2015.07.002

Nielsen, K. (2013). Review Article: How can we make organizational interventions work? Employees and line managers as actively crafting interventions. Human Relations, 66(8), 1029-1050. https://doi.org/10.1177/0018726713477164

Nielsen, K., Randall, R., \& Albertsen, K. (2007). Participants' appraisals of process issues and the effects of stress management interventions. Journal of Organizational Behavior, 28(6), 793-810. https://doi.org/10.1002/job.450

Nytrö, K., Saksvik, P. Ø., Mikkelsen, A., Bohle, P., \& Quinlan, M. (2000). An appraisal of key factors in the implementation of occupational stress interventions. Work \& Stress, 13, 213-225.

Pejtersen, J. H., Kristensen, T. S., Borg, V., \& Bjorner, J. B. (2010). The second version of the Copenhagen Psychosocial Questionnaire. Scandinavian Journal of Public Health, 38(Suppl 3), 8-24. https://doi.org/10.1177/1403494809349858

Randall, R., Nielsen, K., \& Tvedt, S. D. (2009). The development of five scales to measure employees' appraisals of organizational-level stress management interventions. Work \& Stress, 23(1), 1-23. https://doi.org/10.1080/02678370902815277

Authors (2015). A process evaluation of a salutogenic intervention. Scandinavian Psychologist, 2, e8. https://doi.org/10.15714/scandpsychol.2.e8 
Semmer, N. K. (2011). Job stress interventions and organization of work. In J. C. Quick \& L. E. Tetrick (Eds.), Handbook of occupational health psychology (2nd ed., pp. 299318). Washington, D.C.: American Psychological Association.

Tavakol, M., \& Dennick, R. (2011). Making sense of Cronbach's alpha. International Journal of Medical Education, 2, 53-55. https://doi.org/10.5116/ijme.4dfb.8dfd

Undebakke, K. G., Innstrand, S. T., Anthun, K. S., \& Christensen, M. (2015). ARK: The intervention programme: Who - what - how (No. 2015/01). Trondheim: Centre for Health Promotion Research, HIST/NTNU. Retrieved from http://www.ntnu.no/documents/34221120/0/2015_01_ARK_web.pdf 


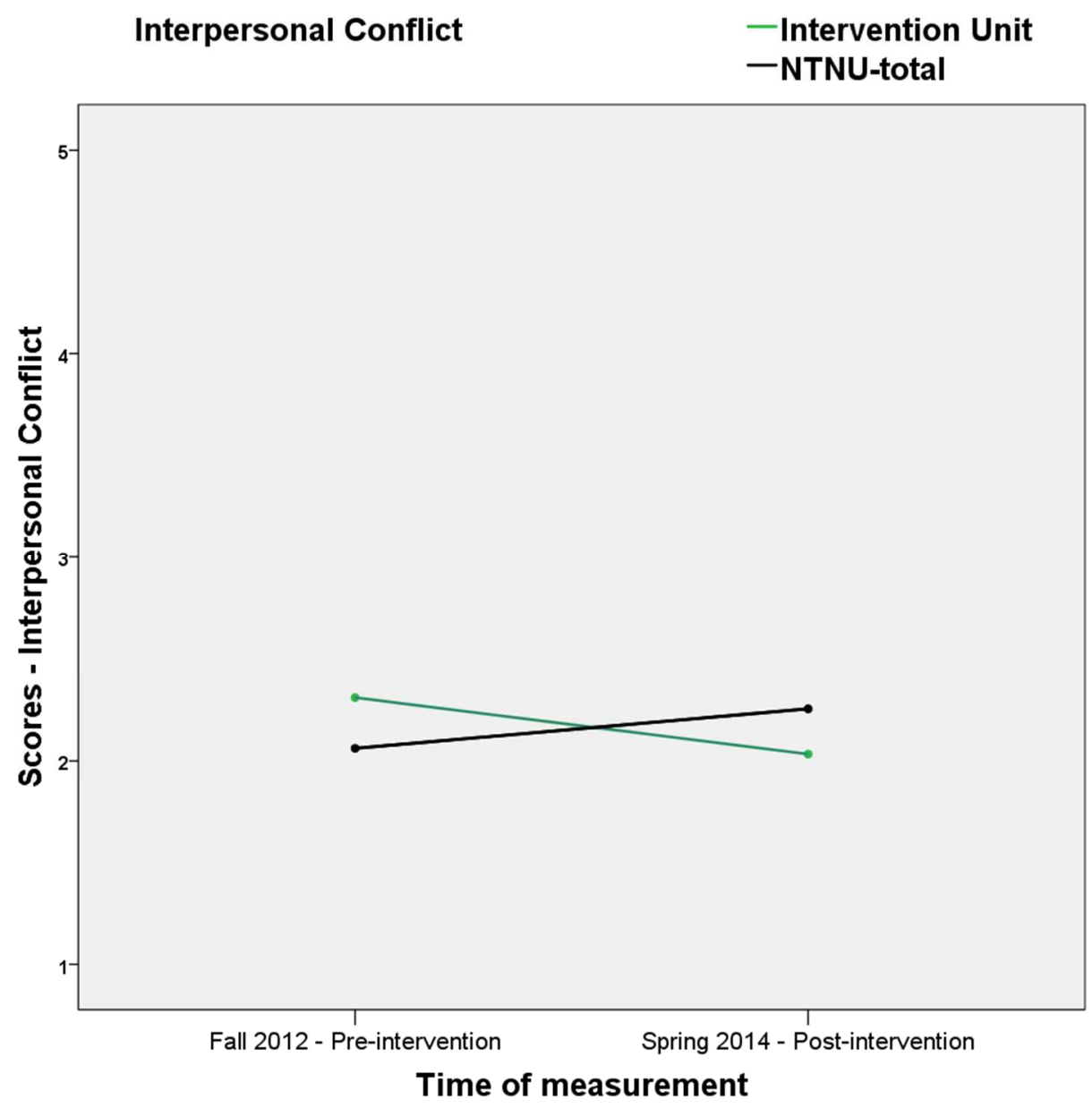

Figure 1 Development over time for Interpersonal Conflict 


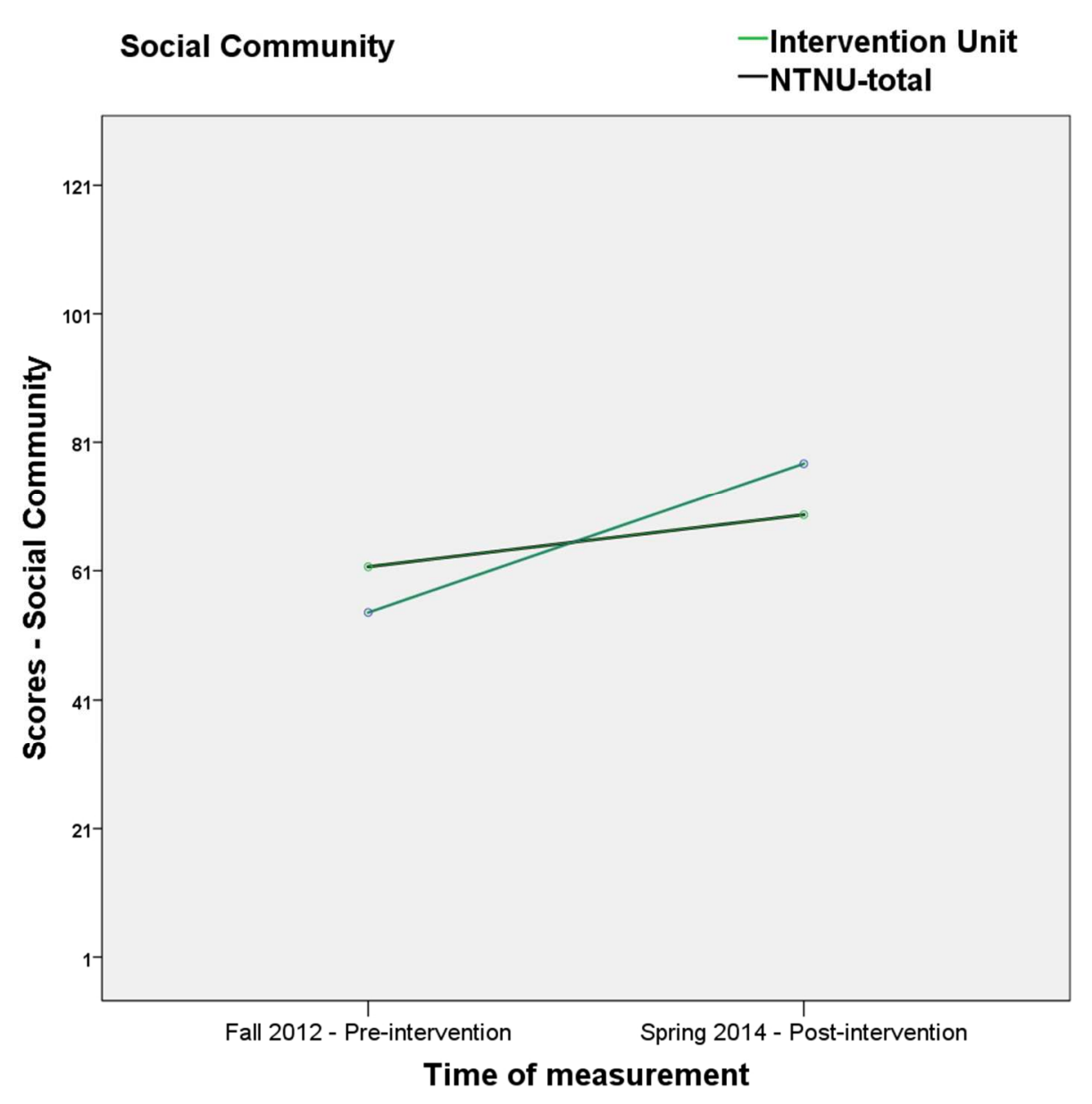

Figure 2 Development over time for Social Community 


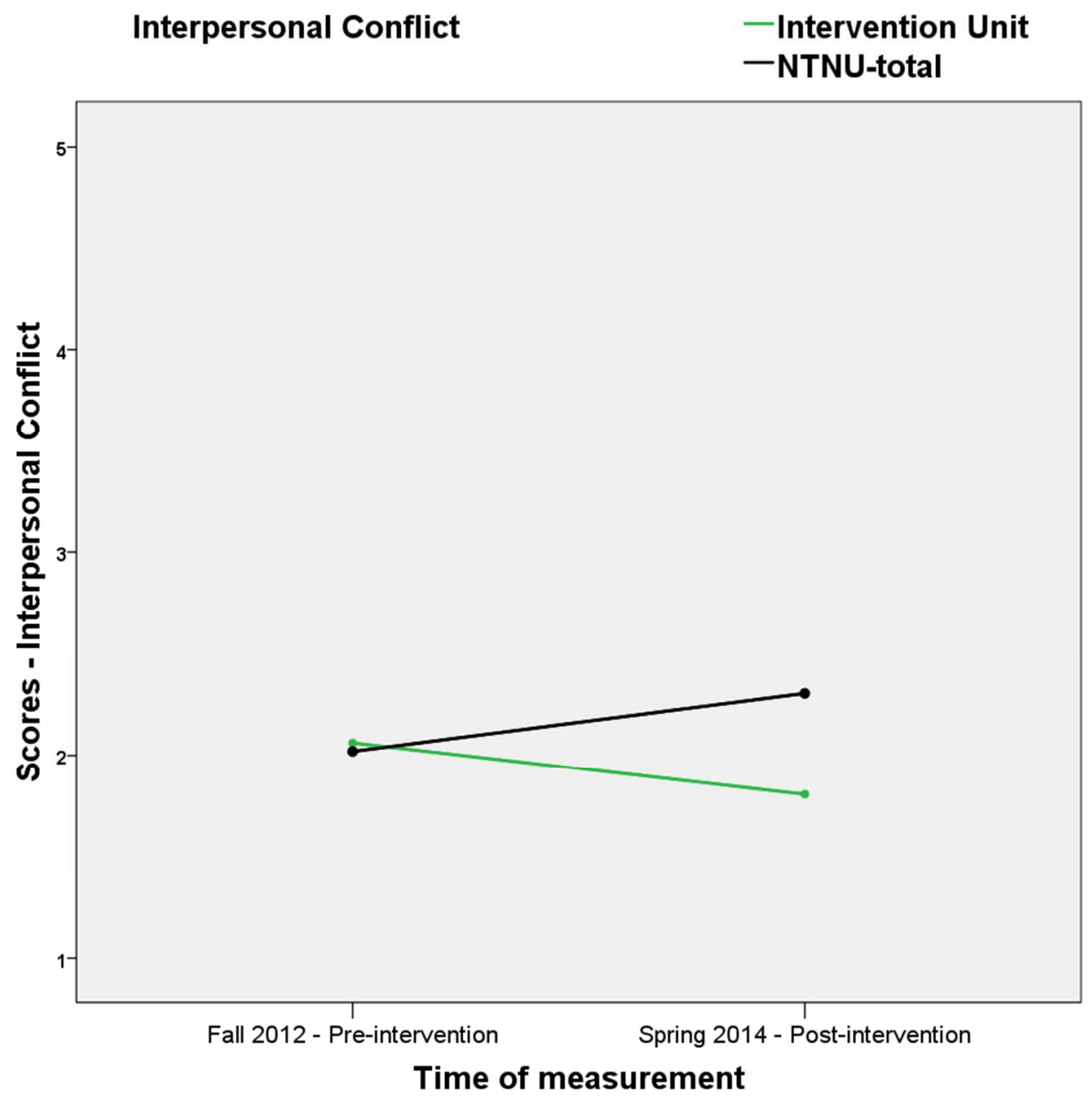

Figure 3 Development over time for Interpersonal Conflict with Leadership and Trust in Management as covariates 


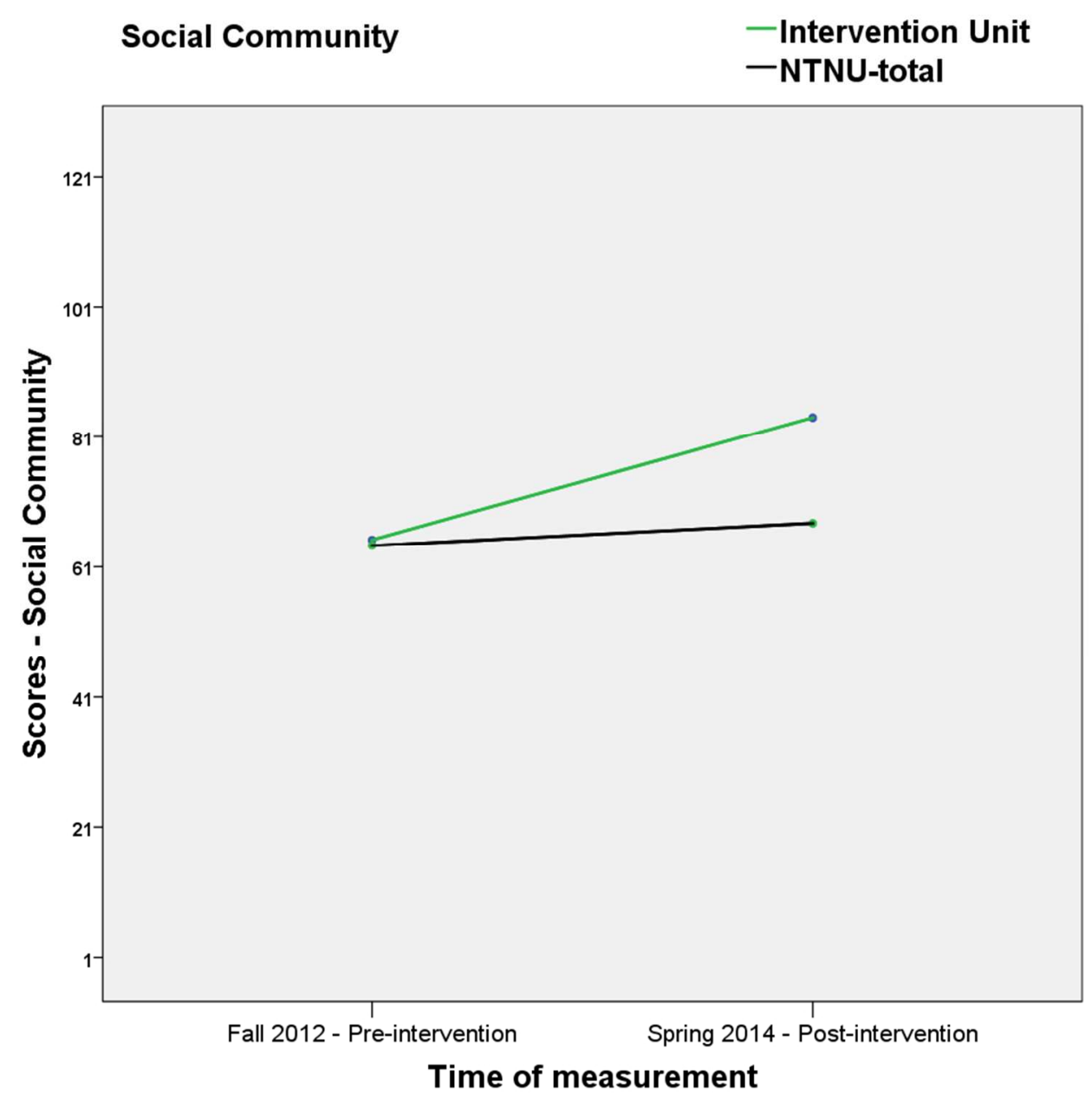

Figure 4 Development over time for Social Community with Leadership and Trust in Management as covariates 
Table 1. Frequency Statistics of Participation in KIWEST

\begin{tabular}{|l|l|l|l|}
\hline Group & Invitations & Responses & Response rate \\
\hline 2012 NTNU (IU not included) & 5,577 & 3,023 & $54.2 \%$ \\
\hline 2012 IU & 60 & 43 & $71.7 \%$ \\
\hline 2014 NTNU (IU not included) & 5,174 & 3,842 & $74.3 \%$ \\
\hline 2014 IU & 63 & 59 & $93.7 \%$ \\
\hline
\end{tabular}

Table 2. Cronbach's alpha for Interpersonal Conflict, Social Community, Empowering Leadership, and Trust in Management before (2012) and after (2014) the intervention.

\begin{tabular}{lll}
\hline Variables & 2012 Pre-intervention & 2014 Post-intervention \\
\hline Interpersonal Conflict & 0.91 & 0.86 \\
Social Community & 0.85 & 0.83 \\
Empowering Leadership & 0.87 & 0.90 \\
Trust in Management & 0.83 & 0.84 \\
\hline
\end{tabular}

